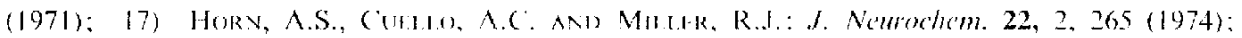
18) Le Moal, M., Galjy, D. and (ardo, B.: Broin Rer. 88, 190 (1975j: 191 Kof, K.B. AND Weissman, A.: Adl. Phamacol. 6, 29 (1968); 20) Kostowski, W., Giacaloni, E., Garattini, S. And Valzeli, L.: Eirop. J. Phamacol. 4, 371 (1968): 21) Korf. J. And Kuiper, H.E.: Psychophamacologia 21, 328 (1971); 22) FUXE, K. AND UvGFrstedT, U.: International Symposium on Amphetamine and Related Compounds. Fdited by Costa, E. And Gakatini, S., p. 257, Raven Press, New York, (1970): 23) KNapP, S., MaNoell, A.J. ANd Geyer, M.A.: J. Pharmacol. exp. Ther. 189, 676 (1974): 24) Brefse, G.R., CoOplr, B.R. avd Muliler, R.A.: Brit. J. Pharmacol. 52, 307 (1974): 25) GRABowskA, M.: Psychopharmacologia 39, 315 (1974)

\title{
EFFECTS OF SOME BILE ACIDS ON HEPATIC BLOOD FLOW IN DOGS - WITH REFERENCE TO BILIARY EXCRETION
}

\author{
Yoshikazu YAMATAKE, Shigeru ISHIKAWA and Saizo YANAURA \\ Department of Pharmacology Hoshi College of Pharmucy. \\ Shinagawa-ku, Tokyo 142, Japan \\ Accepted January 9, 1976
}

The relationship between effects of bile acids on hepatic blood flow and on bile formation has not been extensively studied (1,2). Grodin, et al. (1) pointed out that effects of bile salts on arterial flow to the liver were not essential for a choleretic response. In the present study, we investigated the effects of dehydrocholic acid (DHC), ursodesoxycholic acid (UDC) and chenodesoxycholic acid (CDC) on portal (PBF) and liver-tissue blood flow (LTBF) and on bile formation, and their relationship is discussed.

Male mongrel dogs weighing $913 \mathrm{~kg}$ were fasted for $18 \mathrm{hr}$ before experiments. In the studies on hepatic blood flow, animals were anesthetised with i.v. sodium pentobarbital (15 $\mathrm{mg} / \mathrm{kg})$ and s.c. urethane $(1.2 \mathrm{~g} / \mathrm{kg}$ ) and ventilated artificially via a tracheal cannula. The abdomen was opened by a midline incision. A non-cannulating electromagnetic flow probe (Nihon Kohden Co., Ltd.) was placed around the portal vein to measure PBF (basal flow: 190-260 mlimin), and a wire element of crossed thermocouples (Shincorder CTE-201, Shin-ei Co., Ltd.) was implanted into the free end of the left medial lobe of liver to measure LTBF. Femoral blood pressure was also recorded using a pressure transducer. Drugs were given into the cephalic vein for systemic i.v. injections, or into a small branch of the portal vein via a cannula for intraportal injections. In the studies on biliary secretion, experiments were performed on dogs under sodium pentobarbital $(25 \mathrm{mg} / \mathrm{kg} \mathrm{i.v}$.) anesthesia. The common bile duct was cannulated and the cystic duct was ligated. Biliary outflow from the cannula was measured every $5 \mathrm{~min}$ with a drop counter (basal secretion: $1.5-2.0 \mathrm{ml} / 30 \mathrm{~min}$ ). Animals were infused with physiological saline, $25 \mathrm{ml} / 30 \mathrm{~min}$, during the experiment. All experiments were carried out at a room temp. of $23 \%$ and at a humidity of $65 \%$. Bile acids used were dissolved and neutralized with $\mathrm{NaOH}$ aqueous solution.

In Fig. 1, the results of systemic i.v. injections of the bile acids in doses of 3,10 and 


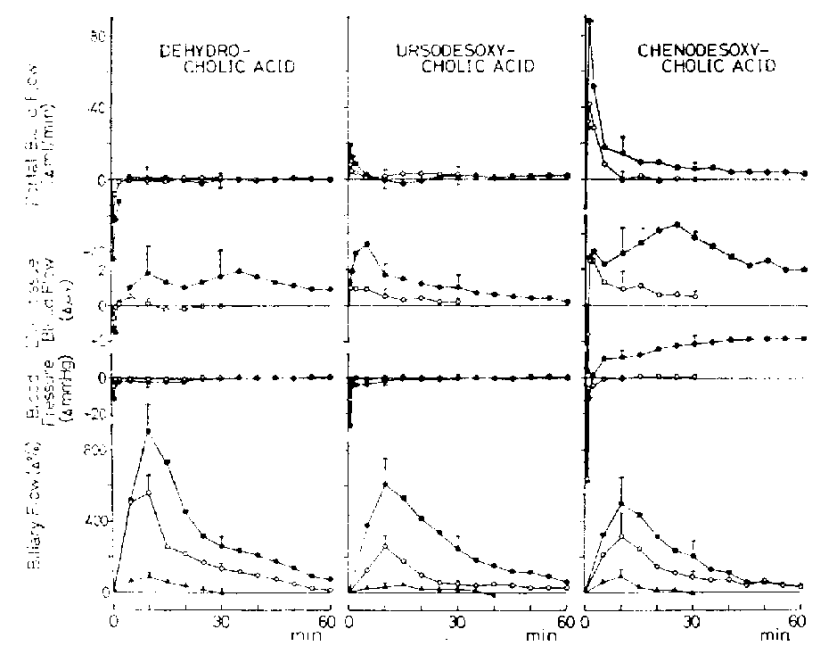

Fici. 1. Eflects of sustemic i.y. administrations of dehydrocholic acid, ursodesoxycholic acid and chenodesoxycholic acid on portal and liver-tissue blood flows, systemic blood pressure, and biliary how in mongrel dogs.

(holeretic activity in cxpressed as " increase in biliary now. Administration of bilc acids $30 \mathrm{mg} \mathrm{kg}$. i... (O). $10 \mathrm{mg} \mathrm{kg}$. i.s. ( '), $3 \mathrm{mg} / \mathrm{kg}$, i.l. (A) was carrical wut at time, respectively.

Fach point represents the mean of six dogs in the experinents of hepatie circulation, and of four dogs in therse of hiliary exerction. Verical bars indicate the S.I. of means at 10 and 30 min after administration.

$30 \mathrm{mg} / \mathrm{kg}$ are shown ( $N-6$ for each agent in the study on hepatic blood flow, and $N=4$ in the study on biliary secretion). The three bile acids used markedly increased volume of biliary outflow, dose-dependently. The order of potency was as follow $\mathrm{DHC}, \mathrm{UDC}>\mathrm{CDC}$. On the other hand, they produced different responses in hepatic circulation. A dose of $10 \mathrm{mg} / \mathrm{kg}$ of DHC and CDC, despite their strong choleretic potency, caused only a transient and slight change in both PBF and LTBF. A dose of $30 \mathrm{mg} / \mathrm{kg}$ moderately increased LTBF for at least 30 min, while PBF was transiently decreased by DHC, and increased by UDC. Among the bile acids used, CDC caused the strongest responses of hepatic and systemic circulation. CDC significantly produced an increase in LTBF following a transient decrease. produced a significant increase in PBF and caused an acute marked hypotension, followed by a hypertension in a dose of $30 \mathrm{mg} \mathrm{kg}$.

Fig. 2 shows the results of intraportal injections of the bile acids in doses of 1 and 3 $\mathrm{mg} / \mathrm{kg}$ ( $\mathrm{N}$ 6 for each agent). PBF and LTBF were not significantly changed after close injections of DHC and UDC into the portal vein, suggesting that DHC and UDC have hardly any direct effect on hepatic circulation. CDC produced, on the other hand, a marked decrease in both PBF and LTBF, accompanied with a rise in systemic blood pressure.

The effects of the bile acids on biliary excretion were not related to their effects on PBF. A dose of $10 \mathrm{mg} / \mathrm{kg}$ i.v. of the bile acids was suffeient to calse a dramatic increase in the volume of biliary outflow, but did not significantly change cither PBF or LTBF. A dose of $30 \mathrm{mg} \cdot \mathrm{kg}$ i.y. of all the bile acids used increased LTBF for more than $60 \mathrm{~min}$. An increase 


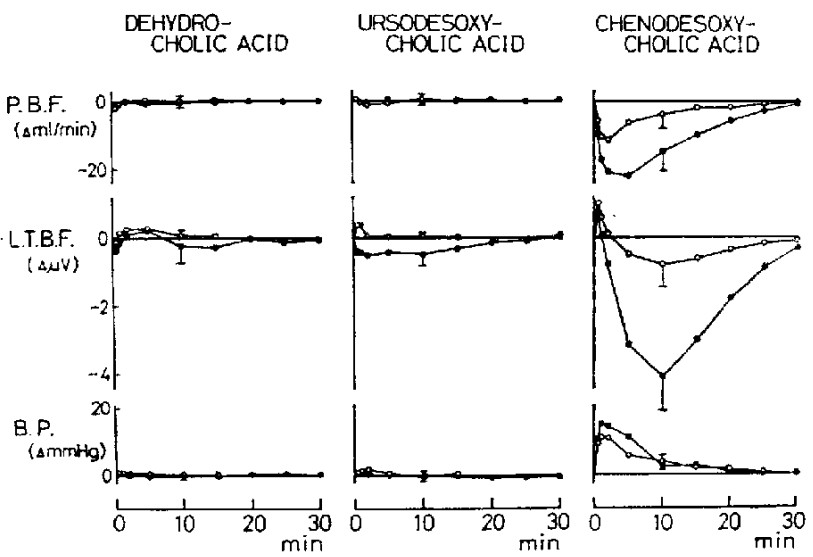

Fig. 2. Effects of intra-portal administrations of dehydrocholic acid, ursodesoxycholic acid and chenodesoxycholic acid on portal blood flow (P.B.F.), liver-tissue blood flow (L.T.B.F.) and systemic blood pressure (B.P.) in mongrel dogs.

Each point represents the mean of six dogs. Vertical bars indicate the S.E. of means at 10 min after administration. Other conditions as in Fig. 1.

in LTBF has been also observed by an i.v. injection of DHC in doses of more than $50 \mathrm{mg} / \mathrm{kg}$ in rats (3). Taking into consideration the fact that with the bile acids used, a prolonged increase of the effect on LTBF was seen with only relatively high doses, and that these effects on LTBF tended to increase progressively, it appears that the increase in LTBF is not a trigger to initiate choleresis, but rather a consequence of choleretic actions of the bile acids. Drapanas, et al. (4) have shown that perfusions of pyruvic or lactic acid into the isolated pig liver resulted in a marked increase in hepatic blood flow. Activation of metabolism in the liver and an enhanced bile formation, therefore, may increase hepatic blood flow via such metabolic substances. Intraportal injections of all the bile acids used caused no increase in either PBF or LTBF; in fact, a decrease was seen with CDC and such is attributed to a contraction of the portal vein and intrahepatic blood vessels.

These findings suggest that there is no significant relationship between the effects of bile acids on biliary excretion and hepatic blood flow.

\section{REFERENCES}

1) Grodins, F.S., Osborne, S.L., IVy, A.C. And Goldman, L.: Am. J. Physiol. 132, 375 (1941); 2) Mizuta, M. and Shinoyama, T.: Acta hepatol.japon. 12, 416 (1971) (in Japanese); 3) KitaGawa, H. ANo Yavo, H.: Pharmacometrics, 7, 1315 (1973) (in Japanese); 4) Drapanas, T., ZEMEL, R., AND VANG, J.O.: Ann. Surg. 164, 522 (1966) 